\title{
Looking under the bonnet of patient-ventilator asynchrony during noninvasive ventilation: does it add value?
}

\author{
Dipansu Ghosh and Mark W. Elliott \\ St James's University Hospital, Leeds, UK.
}

Correspondence: Mark W. Elliott, St James's University Hospital, Beckett Street, Leeds, LS9 7TF, UK. E-mail: mwelliott@doctors.org.uk

@ERSpublications

During noninvasive ventilation it is reasonable to try to abolish clinically apparent patient-ventilator asynchronies but the use of more invasive tests to detect subtle asynchronies cannot be justified http://ow.ly/rXoA30gCm8O

Cite this article as: Ghosh D, Elliott MW. Looking under the bonnet of patient-ventilator asynchrony during noninvasive ventilation: does it add value? ERJ Open Res 2017; 3: 00136-2017 [https://doi.org/10.1183/23120541.00136-2017].

Noninvasive ventilation (NIV) has significant advantages over invasive ventilation in certain situations, such as hypercapnic respiratory failure due to an acute exacerbation of chronic obstructive pulmonary disease (COPD), acute cardiogenic pulmonary oedema, respiratory failure in immunocompromised patients and weaning from invasive ventilation in patients with COPD, in terms of reducing mortality, duration of hospital stay, the need for intubation and infectious complications [1-5].

Effective ventilation requires interaction between the patient and ventilator. The machine must deliver a breath and allow the patient to breathe out when they want. The onset and offset of each part of the respiratory cycle should be synchronous with that of the machine's cycle. A distinction must be made between breaths that are initiated by the machine, usually described as timed or controlled, and those by the patient, assisted or triggered. For an assisted breath, it is important that the ventilator should have a sensitive trigger with a short response time; flow triggers are more sensitive than pressure triggers and are the norm on modern ventilators. The ventilator cycles in to expiration either after a predetermined time, time cycled, or when a predetermined flow rate is achieved, usually a percentage of the peak flow.

The machine can only "see" a patient's inspiratory effort when airflow is detected within the ventilator circuit. Trigger failure may occur either because there is inadequate flow, which can occur in neuromuscular patients with very severe muscle weakness or in patients with COPD with significant intrinsic positive end-expiratory pressure, in whom the first part of the neural inspiratory cycle is spent decompressing positive pressure within the alveoli, rather than delivering inspiratory airflow. Trigger failure will also occur if the trigger sensitivity is low, usually because of an inappropriate setting, or because the presence of a leak makes it easier for air to be drawn in around the mask rather than through the ventilator circuit. Leaks can also affect the machine's ability to cycle into expiration. With a pressure-limited device, the machine will increase flow to try to maintain the preset pressure; as a result, the flow rate does not reach the threshold for cycling into expiration.

Lack of standardisation makes studying the prevalence and severity of asynchrony difficult; most studies have been performed on intubated patients receiving mechanical ventilation. There is no consistency between studies of how and when asynchronies are measured. Because asynchrony may be episodic, short

Received: Oct 312017 | Accepted: Nov 022017

Conflict of interest: Disclosures can be found alongside this article at openres.ersjournals.com

Copyright $\odot$ ERS 2017. This article is open access and distributed under the terms of the Creative Commons Attribution Non-Commercial Licence 4.0. 
periods of observation may miss asynchronies that would be picked up in studies with longer periods of observation, suggesting a higher prevalence, which is not in fact the case. Asynchrony also depends on patient factors that are dynamic and prevalence will also depend on at what point in the patient's journey the observations are made; a higher prevalence is usually found in the first $24 \mathrm{~h} \mathrm{[6].} \mathrm{The} \mathrm{method} \mathrm{of}$ detecting asynchrony also influences the estimation of prevalence. More invasive methods, using oesophageal pressure or electrical activity in the diaphragm (EAdi), allow measurement of inspiratory and expiratory time and effort more precisely. Analysis of ventilator waveforms can be used, but may lead to over- or underestimation of asynchrony [7-9]. Taking all these factors into account, it's not surprising that the prevalence of asynchrony in invasively ventilated patients varies widely, with some studies reporting an asynchrony index (number of asynchronous breaths as percentage of total number) as high as $50-80 \%$ [10-12]. During invasive mechanical ventilation, ineffective efforts represent the most prevalent asynchrony $[12,13]$, mainly due to over-assistance, and can be limited by reducing the amount of support both in terms of tidal volume and inspiratory time $[14,15]$.

Significant levels of asynchrony have also been reported with patients receiving NIV [16-19]. The same limitations described above apply to estimating the prevalence of asynchronies during NIV. This is further compounded by the fact that if asynchrony between the patient and ventilator is a major cause of intolerance, these patients will not be included in any analysis performed in patients established on NIV. In other words, the patients with the worst asynchrony may have been excluded. Vignaux et al. [19] reported an asynchrony index (AI) of $>10 \%$ in $43 \%$ of their patients receiving NIV, with mask leak being the most significant contributor, along with the level of pressure support, in a multivariate analysis. During NIV, in addition to ineffective efforts, autotriggering and delayed cycling appear due to leaks around the mask, and reflect more the ventilator's ability to cope with leak than the settings chosen by the clinician [19, 20]. CARTEAUX et al. [21] showed a much lower level of asynchrony during NIV when dedicated NIV machines were used.

In this issue of ERJ Open Research, LONGHINI et al. [22] present a multicentre study looking at the ability of clinicians to identify asynchronies during NIV using ventilator pressure/flow waveforms. They compared clinicians of varying experience, from different geographical locations and the type of interface used on sensitivity and specificity on the estimation of prevalence of asynchronies during NIV. 70 clinicians (35 with $>3$ years and 35 with $<3$ years, but a minimum 6 months of NIV experience) were shown tracings from 40 patients ( 20 using a face mask and 20 a helmet interface). They were asked to report on the type of asynchronies and whether there was significant asynchrony (defined as AI $>10 \%$ ). The standard was set by three experts independently reviewing the waveforms, with additional information from EAdi. The sensitivity to detect asynchrony by breath-by-breath analysis was low $(\sim 20 \%)$ and was not affected by experience or location but was higher with mask ventilation compared to the helmet. The specificity was high ( 90\%). Significant asynchrony (AI $>10 \%$ ) was present in $18 \%$. The authors concluded that detecting asynchrony solely by inspecting waveforms in NIV is difficult but that invasive means to detect precisely the patient's own respiratory activity, like EAdi, are not feasible for most patients needing NIV. These results are similar to those from studies in invasively ventilated patients. In a study by YounEs et al. [8], $20 \%$ of ineffective breaths were missed by visual waveform analysis. Similarly, CoLомво et al. [9] showed that the ability of intensive care unit (ICU) physicians to recognise patient-ventilator asynchronies by visual analysis of waveforms was low (sensitivity and positive predictive values with breath-by-breath analysis, $22 \%$ and $32 \%$, respectively) and worsens with a higher prevalence of asynchrony. It is surprising that experienced clinicians were no better than the relatively inexperienced; this suggests that detecting asynchronies from waveforms is difficult even for the experienced eye. In other studies in invasively ventilated patients, automated analysis of pressure changes and flow has been used, and had a sensitivity and specificity of $91 \%$ and $96 \%$ of detecting asynchrony, respectively, with an oesophageal balloon used as the reference standard [7]. Other studies have also used computerised algorithms to detect asynchrony [23, 24]. Asynchrony can potentially be recognised earlier and measures taken to correct the cause.

The key question, however, is whether this matters. Do asynchronies that may be subtle and cannot be easily detected have any adverse effect upon outcomes? In theory, in the absence of synchronous activity, the patient does not receive the full benefit of the pressure increase during inspiration, leading to less reduction in the work of breathing and less benefit on gas exchange. Asynchrony may cause patient discomfort and agitation [25]. These factors might reasonably be expected to contribute to failure of ventilation in an unsedated, non-paralysed patient. FABRY et al. [10] showed that seven out of 11 patients studied had "substantial asynchrony", defined as $>10 \%$ breaths untriggered. This arbitrary $10 \%$ cut off has been subsequently adopted in many studies as marker of significant asynchrony and observational studies in invasively ventilated patients have shown that an $\mathrm{AI}>10 \%$ can adversely affect outcomes in terms of longer ICU stay, the need for tracheostomy, survival and the likelihood of discharge home [6, 12, 13]. Asynchrony can also impact outcomes for patients receiving NIV [19]. These studies have all focussed on 
the acute situation. Asynchronies, measured using parasternal electromyography (EMG) with good interobserver reliability, also occur during sleep in patients receiving NIV at home for chronic respiratory failure. In the studies by RAMSAY and co-workers [26, 27], triggering asynchrony was most frequent, observed in $24 \%$ of breaths, followed by ineffective efforts in $16 \%$. Severe asynchrony was identified in the majority of patients, irrespective of the aetiology of the respiratory failure, but did not compromise the effectiveness of NIV in terms of gas exchange. No data were given, however, regarding sleep quality, though in a conference presentation, the same group reported that patient comfort and adherence were unaffected, again questioning the clinical significance of asynchrony.

LoNGHINI et al. [22] mention that the absence of the patient was one of the limitations of their study; this meant that clinicians were unable to see the way that the patient was interacting with the ventilator. It is relatively easy for an experienced clinician to see that the patient is "fighting" the ventilator or that there is significant mask leak. Such obvious asynchrony may be more clinically relevant. Direct observation of the patient is an important clinical skill that is an important part of monitoring of the patient receiving assisted ventilation [28]. Clinical experience and common sense suggest that the patient who appears to be comfortable on a noninvasive ventilator, with apparent good synchrony between patient and machine, is likely to tolerate NIV better than the one who does not. Whether more subtle asynchronies that are not readily apparent to an experienced clinician, and may also not be to the patient, matter remains to be seen.

With current knowledge, it is reasonable to try to abolish clinically apparent asynchronies but the use of more invasive tests to detect subtle asynchronies cannot be justified. The further development of noninvasive techniques, such as computerised wave form analysis or the use of surface EMG, may result in better application of NIV, but it needs to be confirmed in clinical studies whether this impacts upon outcome.

\section{References}

1 Osadnik CR, Tee VS, Carson-Chahhoud KV, et al. Non-invasive ventilation for the management of acute hypercapnic respiratory failure due to exacerbation of chronic obstructive pulmonary disease. Cochrane Database Syst Rev 2017; 7: CD004104.

2 Peter JV, Moran JL, Phillips-Hughes J, et al. Effect of non-invasive positive pressure ventilation (NIPPV) on mortality in patients with acute cardiogenic pulmonary oedema: a meta-analysis. Lancet 2006; 367: 1155-1163.

3 Burns KE, Adhikari NK, Keenan SP, et al. Use of non-invasive ventilation to wean critically ill adults off invasive ventilation: meta-analysis and systematic review. BMJ 2009; 338: b1574.

4 Keenan SP, Mehta S. Noninvasive ventilation for patients presenting with acute respiratory failure: the randomized controlled trials. Respir Care 2009; 54: 116-126.

5 Girou E, Schortgen F, Delclaux C, et al. Association of noninvasive ventilation with nosocomial infections and survival in critically ill patients. JAMA 2000; 284: 2361-2367.

6 de Wit M, Miller KB, Green DA, et al. Ineffective triggering predicts increased duration of mechanical ventilation. Crit Care Med 2009; 37: 2740-2745.

7 Chen $\mathrm{CW}$, Lin WC, Hsu CH, et al. Detecting ineffective triggering in the expiratory phase in mechanically ventilated patients based on airway flow and pressure deflection: feasibility of using a computer algorithm. Crit Care Med 2008; 36: 455-461.

8 Younes M, Brochard L, Grasso S, et al. A method for monitoring and improving patient: ventilator interaction. Intensive Care Med 2007; 33: 1337-1346.

9 Colombo D, Cammarota G, Alemani M, et al. Efficacy of ventilator waveforms observation in detecting patient-ventilator asynchrony. Crit Care Med 2011; 39: 2452-2457.

10 Fabry B, Guttmann J, Eberhard L, et al. An analysis of desynchronization between the spontaneously breathing patient and ventilator during inspiratory pressure support. Chest 1995; 107: 1387-1394.

11 Nava S, Bruschi C, Fracchia C, et al. Patient-ventilator interaction and inspiratory effort during pressure support ventilation in patients with different pathologies. Eur Respir J 1997; 10: 177-183.

12 Thille AW, Rodriguez P, Cabello B, et al. Patient-ventilator asynchrony during assisted mechanical ventilation. Intensive Care Med 2006; 32: 1515-1522.

13 Chao DC, Scheinhorn DJ, Stearn-Hassenpflug M. Patient-ventilator trigger asynchrony in prolonged mechanical ventilation. Chest 1997; 112: 1592-1599.

14 Tassaux D, Gainnier M, Battisti A, et al. Impact of expiratory trigger setting on delayed cycling and inspiratory muscle workload. Am J Respir Crit Care Med 2005; 172: 1283-1289.

15 Thille AW, Cabello B, Galia F, et al. Reduction of patient-ventilator asynchrony by reducing tidal volume during pressure-support ventilation. Intensive Care Med 2008; 34: 1477-1486.

16 Bertrand PM, Futier E, Coisel Y, et al. Neurally adjusted ventilatory assist vs pressure support ventilation for noninvasive ventilation during acute respiratory failure: a crossover physiologic study. Chest 2013; 143: 30-36.

17 Cammarota G, Olivieri C, Costa R, et al. Noninvasive ventilation through a helmet in postextubation hypoxemic patients: physiologic comparison between neurally adjusted ventilatory assist and pressure support ventilation. Intensive Care Med 2011; 37: 1943-1950.

18 Piquilloud L, Vignaux L, Bialais E, et al. Neurally adjusted ventilatory assist improves patient-ventilator interaction. Intensive Care Med 2011; 37: 263-271.

19 Vignaux L, Vargas F, Roeseler J, et al. Patient-ventilator asynchrony during non-invasive ventilation for acute respiratory failure: a multicenter study. Intensive Care Med 2009; 35: 840-846.

20 Schettino GP, Tucci MR, Sousa R, et al. Mask mechanics and leak dynamics during noninvasive pressure support ventilation: a bench study. Intensive Care Med 2001; 27: 1887-1891. 
21 Carteaux G, Lyazidi A, Cordoba-Izquierdo A, et al. Patient-ventilator asynchrony during noninvasive ventilation: a bench and clinical study. Chest 2012; 142: 367-376.

22 Longhini F, Colombo D, Pisani L, et al. Efficacy of ventilator waveform observation for detection of patient-ventilator asynchrony during NIV: a multicentre study. ERJ Open Res 2017; 3: 00075-2017.

23 Cuvelier A, Achour L, Rabarimanantsoa H, et al. A noninvasive method to identify ineffective triggering in patients with noninvasive pressure support ventilation. Respiration 2010; 80: 198-206.

24 Mulqueeny Q, Redmond SJ, Tassaux D, et al. Automated detection of asynchrony in patient-ventilator interaction. Conf Proc IEEE Eng Med Biol Soc 2009; 2009: 5324-5327.

25 Carlucci A, Pisani L, Ceriana P, et al. Patient-ventilator asynchronies: may the respiratory mechanics play a role? Crit Care 2013; 17: R54.

26 Ramsay M, Mandal S, Suh ES, et al. Effects of patient ventilator asynchrony (PVA) on gas exchange, respiratory muscle load, patient comfort and adherence to non-invasive ventilation (NIV). Eur Respir J 2014; 42: Suppl. 57, 1975

27 Ramsay M, Mandal S, Suh ES, et al. Parasternal electromyography to determine the relationship between patient-ventilator asynchrony and nocturnal gas exchange during home mechanical ventilation set-up. Thorax 2015; 70: 946-952.

28 Tobin MJ. Respiratory monitoring in the intensive care unit. Am Rev Respir Dis 1988; 138: 1625-1642. 